\title{
Reaproveitamento do resíduo da madeira de eucalipto (RME) para a produção de energia sustentável.
}

Reuse of eucalyptus wood residue (EWR) for sustainable energy production.

Reutilización de resíduos de madera de eucalipto (RME) para la producción de energia sostenible.

Sabrina Pereira da Silva Graduanda, UNESP - Ilha Solteira, Brasil sabrinapdantas@gmail.com

Jorge Luis Akasaki Professor Doutor, UNESP - Ilha Solteira, Brasil jorge.akasaki@gmail

Alex Otávio Sanches Pós-Doutorando, UNESP - Ilha Solteira, Brasil alexosanches@gmail.com 


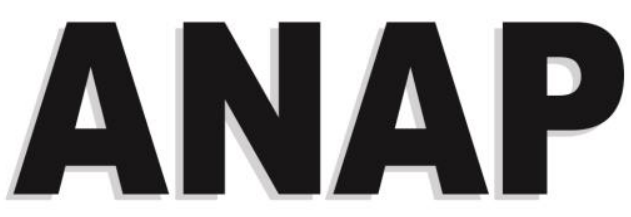

\section{RESUMO}

As pesquisas relacionadas a utilização de materiais sustentáveis na geração de energia limpa têm sido largamente difundidas em escala global. Com o aumento crescente na utilização de combustíveis fósseis como principal fonte produtora de energia, para as mais diversas finalidades exercidas pelo homem, tem-se a necessidade de se buscar outros materiais, principalmente os renováveis, para suprir a demanda de energia de maneira sustentável e economicamente viável. Neste cenário, tem-se a biomassa como excelente alternativa. A utilização da biomassa madeireira nas mais diversas formas gera um resíduo denominado de cinzas ou fuligem e, devido ao aumento no uso da bioenergia, também houve o aumento significativo no volume de cinzas oriundos deste biocombustível. Desta forma, tem-se como grande desafio a gestão destes materiais seja no reaproveitamento, armazenamento e descarte adequado do mesmo. Com a proposta de se utilizar novas alternativas para a geração de energia limpa, este projeto visa estudar a viabilidade de se usar o resíduo da madeira de eucalipto (RME) como biocombustível sólido (briquetes) gerando, por sua vez, energia sustentável e economicamente viável. Para isto, foram feitas as caracterizações físico-química deste material no que tange a difração de raio-x (DRX), termogravimetria (TG/DTG) e calorimetria exploratória diferencial (DSC), bem como foi determinado empiricamente o melhor traço destes biocombustíveis sólidos.

PALAVRAS-CHAVE: Energia. Renováveis. Biomassa.

\section{ABSTRACT}

Research on the use of sustainable materials in clean energy generation has been widely disseminated on a global scale. With the increase in the use of fossil fuels as the main source of energy for the most diverse purposes pursued by man, there is a need to look for other materials, especially renewable ones, to supply the energy demand in an economically viable and sustainable manner. In this scenario, biomass is an excellent alternative. The use of wood biomass in many processes generates a residue called ash or soot and, due to the increased use of bioenergy, there has been a significant increase in the volume of ash from this biofuel. Thus, the management of these materials is a great challenge, whether in reuse, storage and proper disposal. With the proposal of using new alternatives for the generation of clean energy, this project aims to study the viability of using eucalyptus wood residue (EWR) as solid biofuel (briquettes) generating, in turn, sustainable and economically viable energy. For this, the physicochemical characterizations of this material were made regarding X-Ray diffraction (XRD), thermogravimetry (TG/DTG) and differential scanning calorimetry (DSC), as well as the empirically determined best trace of these solid biofuels.

KEYWORDS: Energy. Renewable. Biomass.

\section{RESUMEN}

La investigación sobre el uso de materiales sostenibles en la generación de energía limpia se ha difundido ampliamente a escala mundial. Con el aumento creciente en el uso de combustibles fósiles como la principal fuente de energía para los propósitos más diversos perseguidos por el hombre, existe la necesidad de buscar otros materiales, especialmente los renovables, para abastecer la demanda de energía de una manera sostenible y sostenible. económicamente viable En este escenario, la biomasa es una excelente alternativa. El uso de biomasa de madera en las formas más diversas genera un residuo llamado ceniza o hollín y, debido al mayor uso de bioenergía, también hubo un aumento significativo en el volumen de cenizas de este biocombustible. Por lo tanto, la gestión de estos materiales es un gran desafí, ya sea en la reutilización, el almacenamiento y la eliminación adecuada. Con la propuesta de utilizar nuevas alternativas para la generación de energía limpia, este proyecto tiene como objetivo estudiar la viabilidad del uso de residuos de madera de eucalipto (RME) como biocombustible sólido (briquetas) que genera, a su vez, energía sostenible y económicamente viable. Para esto, se realizaron las caracterizaciones fisicoquímicas de este material con respecto a la difracción de rayos $X$ (DRX), termogravimetría (TG / DTG) y calorimetría exploratoria diferencial (DSC), así como la mejor traza de estos biocombustibles sólidos se determinó empíricamente.

PALABRAS CLAVE: Energía. Renovable. Biomasa. 

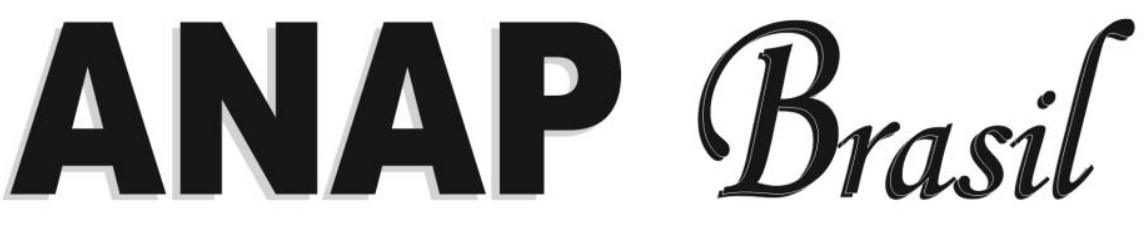

ISSN 1984-3240 v. 13, n. 28

\section{REVISTA CIENTÍFICA}

2020

\section{INTRODUÇÃO}

\subsection{MADEIRA DE EUCALIPTO}

Há mais de um século, no Brasil, os plantios da árvore de eucalipto começaram. Navarro de Andrade em 1903 foi o pioneiro a trazer as mudas ao cerrado paulista para plantios que produziam madeira para dormentes das estradas de ferro. A variação climática no Brasil é muito grande e, neste cenário, o eucalipto se destaca devido a sua fácil adaptação e, além disso, este plantio tem-se estendido além das regiões tradicionais sul e sudeste. O Brasil detém hoje as melhores tecnologias na silvicultura de Eucalyptus, atingindo cerca de $60 \mathrm{~m}^{3} / \mathrm{ha}$ de produtividade, em rotação de sete anos (SANTIAGO, 2013).

O setor florestal relacionado ao plantio de eucalipto e pinus no Brasil são plantados e manejados de forma a atender a demanda dos mercados de siderúrgica, painéis, móveis, bioenergia, óleo de soja, construção civil e papel e celulose. Em 2011, a área ocupada por plantios florestais de Eucalyptus e Pinus no Brasil totalizou 6.515 .844 ha, sendo $74,8 \%$ correspondente a área de plantios de Eucaliptus e $25,2 \%$ ao plantio de Pinus. Além disso, o setor de papel e celulose concentra $71,2 \%$ da área plantada, e além desta árvore ser utilizada no processo fabril, é uma alternativa de preservação da natureza contra a devastação das florestas (ABRAF, 2012).

Ainda de acordo com o autor supracitado, $38,7 \%$ da madeira da floresta plantada foram destinadas a produção de carvão vegetal e lenha, 35,2\% foram utilizadas para a produção de celulose nas indústrias de papel e celulose, $16,4 \%$ na produção de cerrados, $7,1 \%$ para a produção de painéis de madeira industrializada e $2,7 \%$ na produção de compensados.

O potencial energético do eucalipto e sua rentabilidade econômica mostraram-se vantajosos quando a partir do uso de cavacos de eucalipto, a uma umidade média de $49,47 \%$, constatouse que para atingir a mesma energia obtida na queima de $1 \mathrm{~m}^{3}$ deste material seriam necessários $72 \mathrm{~kg}$ de óleo combustível, 220,39 KWh de energia elétrica, ou ainda, $105 \mathrm{~kg}$ de carvão mineral (GONZALEZ, 2014).

\subsection{IMPORTÂNCIA DA BIOMASSA DA MADEIRA DE EUCALIPTO}

Define-se biomassa como sendo a massa orgânica produzida por unidade de área, podendo ser expresso em peso de matéria seca, peso de matéria úmida ou peso de carbono (SOARES; NETO; SOUZA, 2011).

A biomassa pode ser basicamente de três tipos, tais como: florestal, agrícola e oriunda de rejeitos urbanos e industriais. A primeira está relacionada, principalmente à utilização da madeira. Já a segunda, por sua vez, está relacionada à produção agrícola de insumos como o arroz, soja, cana-de-açúcar, entre outras. E a terceira, por fim, está diretamente associada aos rejeitos urbanos e industriais despejados pelo homem na natureza. Os derivados obtidos dependem da matéria-prima utilizada e cujo potencial energético é variável, ou seja, depende do material empregado assim como da tecnologia de processamento utilizada (ANEEL, 2012). 

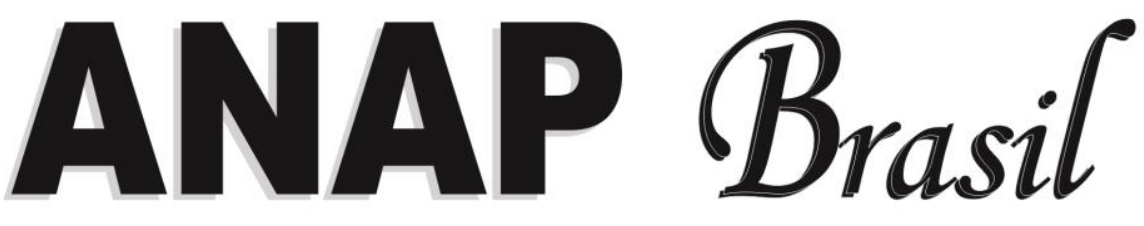

ISSN 1984-3240 v. 13, n. 28

\section{REVISTA CIENTÍFICA}

A madeira de eucalipto é utilizada em grande escala atualmente e participa da matriz energética mundial, variando de intensidade conforme o desenvolvimento do país, disponibilidade das florestas e competição econômica com outras fontes de energia. Há alguns anos as atividades relacionadas à madeira visava a busca apenas do produto principal. Hoje, muitas empresas de posição de destaque utilizam os resíduos gerados para diversas finalidades, sendo elas: utilização dos resíduos em cerâmicas, argamassas e concretos, geração de energia, entre outros (SANTIAGO, 2013).

A produção de energia em larga escala a partir da biomassa vem sendo estudada em vários países do mundo. No caso brasileiro, as oportunidades mais reais estão no uso mais eficazes da biomassa em sistemas de cogeração industrial (WALTER, 1998).

Pode-se afirmar, portanto, que a utilização da biomassa madeireira apresenta vantagens ambientais e sociais. O primeiro está relacionado à substituição de combustíveis fósseis e pela redução de gases de efeito estufa, já o segundo, por sua vez, gera emprego local para a região (JACOVINE et al., 2001).

\subsection{SETOR ENERGÉTICO BRASILEIRO}

Sabe-se que há um aumento no consumo de energia no Brasil e isto se dá, principalmente, devido ao aumento populacional, bem como o aumento no consumo per capita. Desta maneira, houve uma necessidade de tentar suprir essa demanda de energia e existem duas formas de obtenção da mesma que são as fontes renováveis e as não renováveis. As fontes renováveis são aquelas respostas pela natureza e tem-se como principais exemplos a energia eólica e hidráulica. Já as fontes não renováveis, por sua vez, são aquelas em que a natureza necessita de um tempo geológico para a reposição e tem-se como principais exemplos a energia gerada por combustíveis fósseis e nuclear (GOLDEMBERG; LUCON, 2007).

O Brasil tem sua matriz energética baseada nas usinas hidrelétricas de médio a grande porte e, desta forma, em 2001 a crise de energia causada pela baixa ocorrência de chuvas, bem como pela falta de investimento na capacidade de geração e transmissão de energia hidrelétrica, evidenciou ainda mais a necessidade de diversificação e expansão de outros setores geradores de energia. Entre os anos de 1990 e 2000, a produção de eletricidade teve um aumento médio anual de 4,6\%, enquanto que a capacidade instalada aumentou somente 3,1\%. Deste modo, com o aumento do consumo os reservatórios de água baixaram consideravelmente além do esperado e o sistema tornou-se bastante dependente da quantidade anual de chuvas. A solução deste problema foi pautada na política do racionamento de energia, esta durou 10 meses e foi compreendida entre o período de 01 de Julho de 2001 à 01 de Março de 2002. Este racionamento foi bastante agravante tanto para o setor elétrico quanto para a economia brasileira (INTERNACIONAL ENERGY AGENCY, 2003).

Ainda de acordo com o autor supracitado, futuramente as construções de usinas hidrelétricas podem ser inviáveis, visto que, os recursos hídricos remanescentes estão longe dos grandes polos consumidores requerendo, portanto, grandes investimentos em linhas de transmissão. 

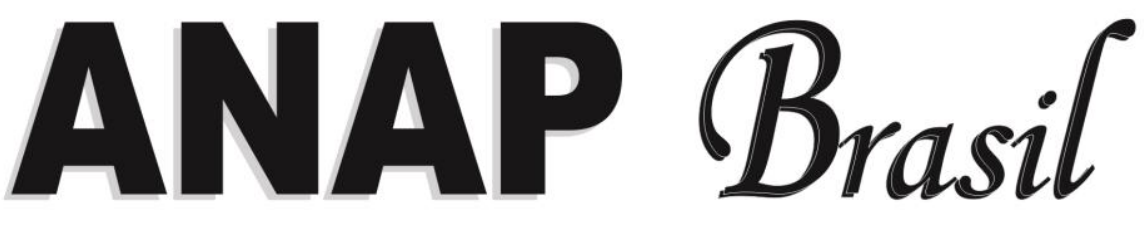

ISSN 1984-3240 V. 13, n. 28

\section{REVISTA CIENTÍFICA}

Além disso, deve-se considerar as questões ambientais, uma vez que, grande parte deste potencial está localizada na região Amazônica.

Aumentar a diversificação da matriz energética é reduzir a sua dependência de combustíveis fósseis, bem como de hidrelétricas, sendo uma medida estratégica importante para assegurar o suprimento de energia. Deste ponto de vista, não se fica vulnerável às oscilações de preço do mercado, instabilidades políticas e dependência direta dos períodos de chuva (COELHO, 2005). A energia é de suma importância para o desenvolvimento social e econômico de um país, e as previsões relatam que a oferta de petróleo não atende a demanda crescente da população. Desta forma, se faz necessário a adoção de fontes alternativas de energia, principalmente as renováveis, e é neste cenário que a biomassa se encaixa. Além disso, as questões referentes ao aquecimento global, bem como as mudanças climáticas são aspectos importantes a se considerar e evidenciar a necessidade de incorporação, no processo de desenvolvimento, de tecnologias eficientes e modernas de energia sustentável (GOLDEMBERG; VILLANUEVA, 2003).

\subsection{CINZAS ORIUNDAS DA COMBUSTÃO DA BIOMASSA}

As cinzas ou fuligem oriundas da combustão da biomassa é a parte inorgânica não-combustível que resultou após o processo de degradação termoquímica da lenha (KHAN, 2009). Estes resíduos podem ter propriedades físico-químicas distintas e que podem estar relacionadas a fatores como a origem da biomassa, o tipo de procedimento utilizado para o aproveitamento de energia, bem como as reações ocorridas durante o processo térmico envolvidos na degradação (LÖVGREN, 2012).

Tem-se que os elementos mais encontrados na formação das cinzas da biomassa são aqueles comumente conhecidos como metais alcalinos, metais alcalino-terrosos, sílica e enxofre, ou seja, $\mathrm{Ca}, \mathrm{Si}, \mathrm{Al}, \mathrm{Ti}, \mathrm{Fe}, \mathrm{Mg}, \mathrm{Na}$, k, S e P. Além disso, pode-se verificar nestes resíduos, também, a presença de alguns metais pesados, que estão associados principalmente às cinzas de fundo, $\mathrm{e}$ que são prejudiciais tanto à vida humana quanto ao ambiente se manejados de maneira errônea. Por este motivo, é de suma importância conhecer a composição da fuligem antes do seu descarte (KHAN et al., 2009; OLANDERS et al., 1994).

A quantidade de cinzas geradas está associada a ineficiência da queima da lenha nas caldeiras e fornos. Estes resíduos têm sua coloração variando de tonalidade sendo este fator, portanto, relacionado ao grau de eficácia da queima. Desta forma, algumas caldeiras possuem grandes potenciais inovadores e são capazes de fazer toda a degradação e queimando, contudo, todo o carbono existente. A fuligem cuja coloração é preta mostra que neste material existe carbono presente na composição e que não foi degradado e, por outro lado, tem-se que nestes resíduos cuja coloração é tipicamente cinza clara há pouca ou nenhuma presença deste elemento (BORTOLETTO et al., 2017).

A variação na quantidade de carbono presente nas cinzas é objeto de estudo de diversos pesquisadores. Segundo Gomes-Barea et al. (2009), este componente está presente nos resíduos na proporção de $10 \%$ a $60 \%$ da massa das cinzas. Já de acordo com Duan et al. (2012) 


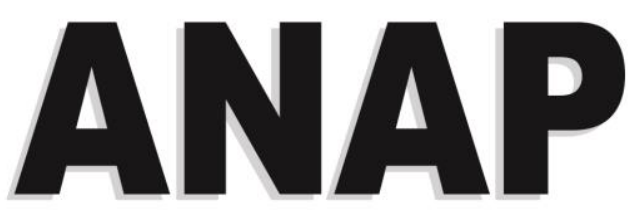

Brasil

ISSN 1984-3240

\section{R E V I S TA}

\section{I E N TÍ F I C A}

sugeriram que o mesmo está presente em torno de $10 \%$ a $30 \%$. Ainda com base nos últimos autores, há duas razões possíveis para justificar o teor de carbono presentes na fuligem, tais como: o curto tempo de permanência da madeira na caldeira e/ou nos fornos gerando, contudo, a queima incompleta do carvão; e, a segunda razão, está ligada as camadas de cinzas que são formadas durante o processo de degradação termoquímica e que impedem a passagem dos gases para o núcleo da lenha contribuindo, portanto, para que a mesma tenha a combustão incompleta.

Demirbas (2005) propôs que estas cinzas com o elemento carbono presente na sua composição poderiam ser utilizadas como combustíveis para as caldeiras e que, desta forma, estes resíduos substituíram cerca de $1 \%$ a $2 \%$ do combustível que seria utilizado contribuindo, por sua vez, para a redução do consumo deste insumo, bem como nas emissões de NOx. Embora as cinzas provenientes da biomassa seja uma excelente opção para a geração de energia, tem-se que tomar cuidado e se investigar minuciosamente os elementos formadores destes materiais, pois alguns componentes poderiam limitar este processo de combustão nas caldeiras, principalmente devido aos processos relacionados a corrosão que são típicos de compostos como o $\mathrm{K}_{2} \mathrm{O}$ e $\mathrm{HCl}$.

\section{OBJETIVO}

O objetivo principal deste projeto é estudar a viabilidade em se utilizar as cinzas geradas pela queima da madeira de eucalipto durante o processo de fabricação de óleo de soja pela indústria COMIGO para a requeima e produção de energia. O principal foco deste trabalho é o de aproveitar este subproduto oriundo das caldeiras da indústria goiana para formar um novo sólido, denominados briquetes, que possuam propriedades caloríficas suficientes e que sejam capazes de gerar energia de tal maneira que seja sustentável e viável economicamente.

\section{MATERIAIS E MÉTODOS}

\subsection{MATERIAIS UTILIZADOS}

\subsubsection{CINZAS DAS MADEIRAS DE EUCALIPTO}

As cinzas da madeira de eucalipto utilizadas neste projeto foram aquelas oriundas da Cooperativa Agroindustrial dos Produtores Rurais do sudoeste Goiano (COMIGO) da cidade de Rio verde, localizada no sudoeste de Goiás. Tem-se na Figura 1 abaixo uma representação do material na sua forma bruta. 


\section{REVISTA CIENTÍFICA 2020}

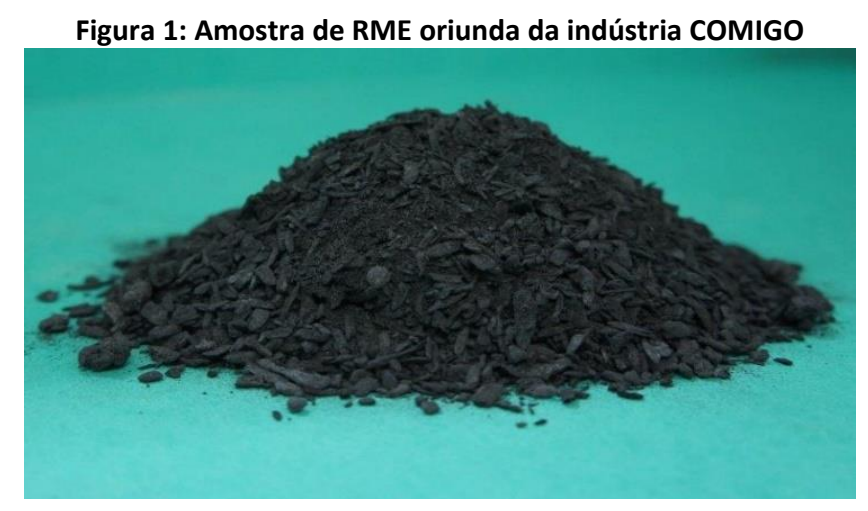

Fonte: PRÓPRIOS AUTORES, 2019.

\subsubsection{AMIDO DE MILHO}

O ligante utilizado neste projeto foi o amido de milho da marca SIAMAR disponível no Laboratório Central de Engenharia Civil da UNESP do campus de Ilha Solteira - SP.

\subsection{3. ÁGUA}

A água utilizada nos ensaios foi aquela oriunda do abastecimento público, destinada ao consumo dos habitantes de Ilha Solteira - SP.

\subsection{METODOLOGIA}

A metodologia foi estruturada da seguinte maneira:

Inicialmente, as propriedades físico-químicas do resíduo da madeira de eucalipto (RME) oriundo da Indústria COMIGO foi analisada com a finalidade de se obter a mineralogia completa do material, esta análise feita por meio da difração de raio-X (DRX). Além disso, também foram feitas a análise termogravimétrica (TG e DTG) e calorimetria exploratória diferencial (DSC), no intuito de se caracterizar, de maneira complementar, a composição do material bem como suas reações de transformação térmica.

Em segunda etapa, foram feitas as análises supracitadas, no entanto, o material de análise desta vez foi o resíduo da madeira de eucalipto (RME) puro, porém calcinado. Tal processo foi feito para se obter uma comparação dos resultados encontrados nesta experimentação com àqueles encontrados anteriormente para a cinza bruta sem tratamento e sem calcinar.

Em seguida, foram moldados os briquetes que são os corpos-de-prova moldados com o RME, água e aglutinante em diferentes proporções (5\%,10\% e 15\%), bem como também foram moldados sem o ligante. Estes biocombustíveis foram levados ao forno Mufla para calcinação a 600 ㄷ por $6 \mathrm{~h}$. Com as cinzas oriundas do processo de queima foram coletadas pequenas amostras para a realização da caracterização físico-química por meio da Difração de Raio-x (DRX). 


\section{ANAP \\ Brasil \\ ISSN 1984-3240 v. 13, n. 28}

\section{REVISTA C IENTÍFICA}

\section{RESULTADOS E DISCUSSÃO}

\subsection{CARACTERIZAÇÃO FÍSICO-QUÍMICA DO RME TRATAMENTO E DO RME CALCINADO}

Inicialmente foi feito a caracterização físico-química do resíduo da madeira de eucalipto (RME), na sua forma bruta e sem tratamento, por meio da difração de raio-x (DRX) para a obtenção da mineralogia do material. $O$ resultado deste ensaio é apresentado na Figura 2.

Figura 2: Difratograma de Raio-x do RME sem tratamento

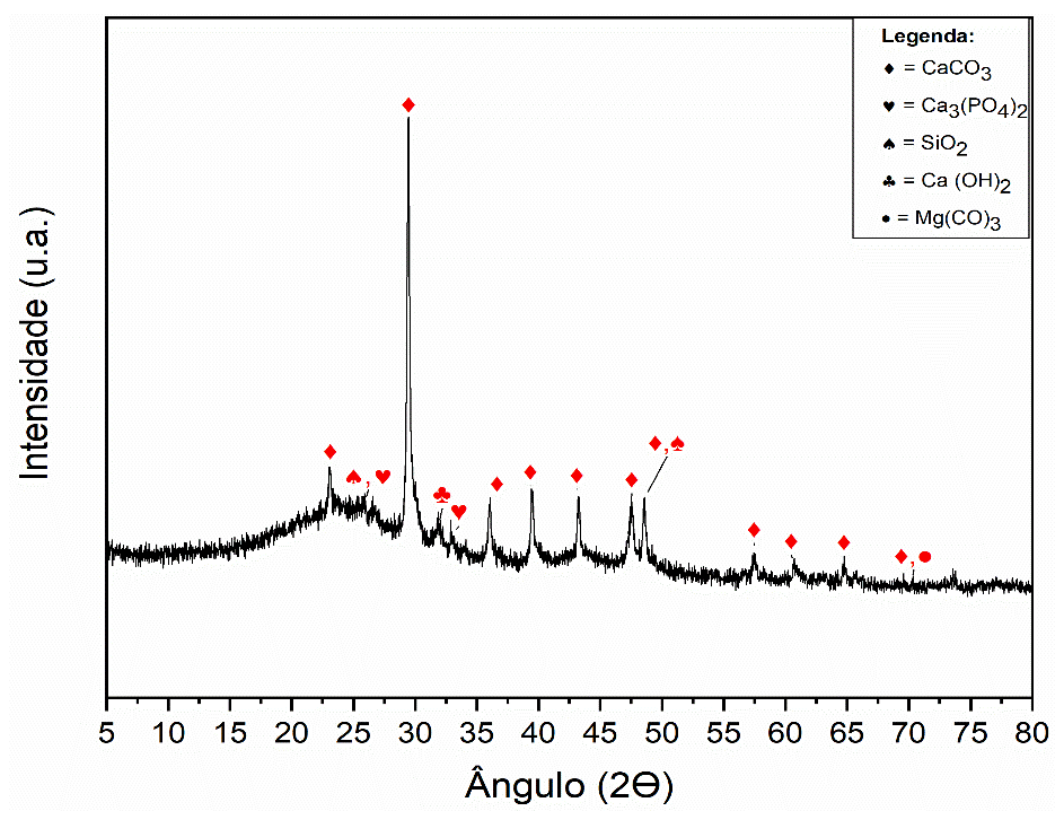

Fonte: PRÓPRIOS AUTORES, 2019.

O difratograma da amostra RME apresentou uma banda amorfa na região $2 \theta$ igual 15 - 35은 aproximadamente, o que pode representar a presença de matéria orgânica e outros derivados amorfos. Pode-se notar, também, a presença significativa do elemento carbono (C) nas mais diversas composições ( $\mathrm{CaCO} 3$ e $\mathrm{MgCO} 3$ ), o que caracteriza a coloração preta da fuligem. $\mathrm{O}$ principal composto foi determinado como sendo o carbonato de cálcio (CaCO3), apresentando

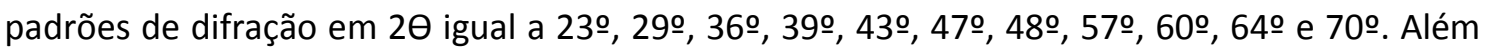
disso, outros compostos foram encontrados, tais como o fosfato de cálcio (Ca3(PO4)2), dióxido de silício ou quartzo ( $\mathrm{SiO} 2)$, hidróxido de cálcio $(\mathrm{Ca}(\mathrm{OH}) 2)$ e carbonato de magnésio $(\mathrm{Mg}(\mathrm{CO}) 3)$.

A Figura 3 apresenta os difratogramas de DRX da amostra RME calcinada a $600^{\circ} \mathrm{C}$ durante $6 \mathrm{~h}$ comparativamente a amostra sem tratamento. 


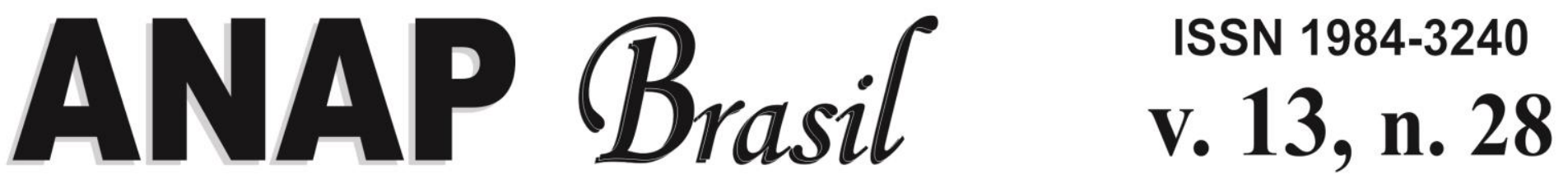

\section{REVISTA C I ENTÍFICA $\quad 2020$}

Figura 3: Difratograma de Raio-x do RME sem tratamento e o calcinado

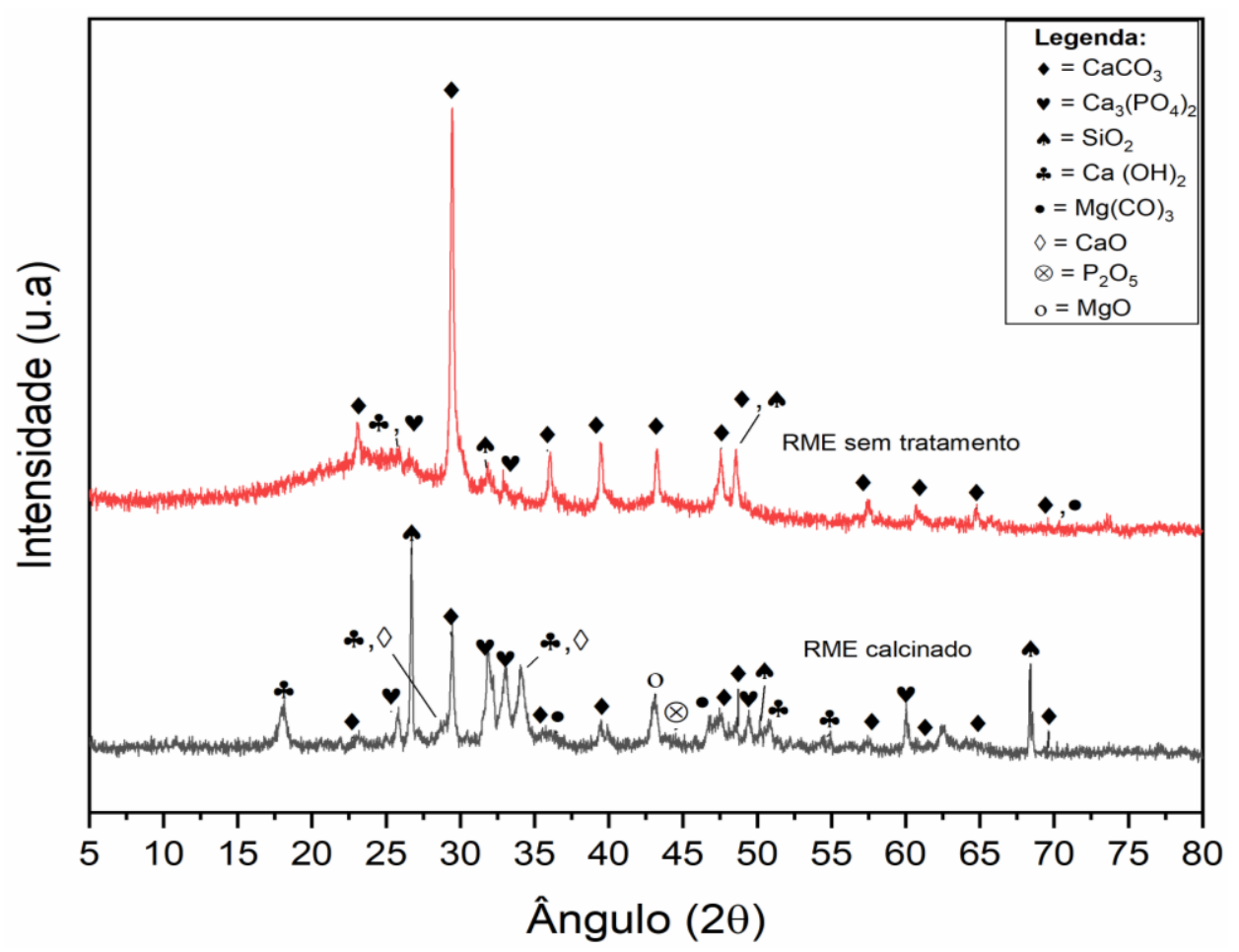

Fonte: PRÓPRIOS AUTORES, 2019.

Comparando as amostras, verificou-se que a banda amorfa encontrada no RME sem tratamento desapareceu no RME calcinado e isto ocorreu, muito provavelmente, devido à queima e degradação da matéria orgânica residual, que pode ser comprovado pelas análises termogravimétricas (TG). Notou-se, ainda, que a mineralogia é basicamente a mesma, ou seja, há a presença significativa de carbono (C) cujo principal composto formado por este elemento é o carbonato de cálcio (CaCO3), soma-se a isto, padrões de difração referentes a compostos como o óxido de cálcio $(\mathrm{CaO})$ e óxido de magnésio $(\mathrm{MgO})$ resultante da descarbonatação parcial do carbonato de cálcio ( $\mathrm{CaCO} 3)$ e do carbonato de magnésio $(\mathrm{Mg}(\mathrm{CO}) 3)$.

Para complementar os resultados obtidos acima, fez-se a análise termogravimétrica (TG) para o RME sem tratamento como se segue por meio da Figura 4. 


\section{ANAP

\section{REVISTA CIENTÍFICA 2020}

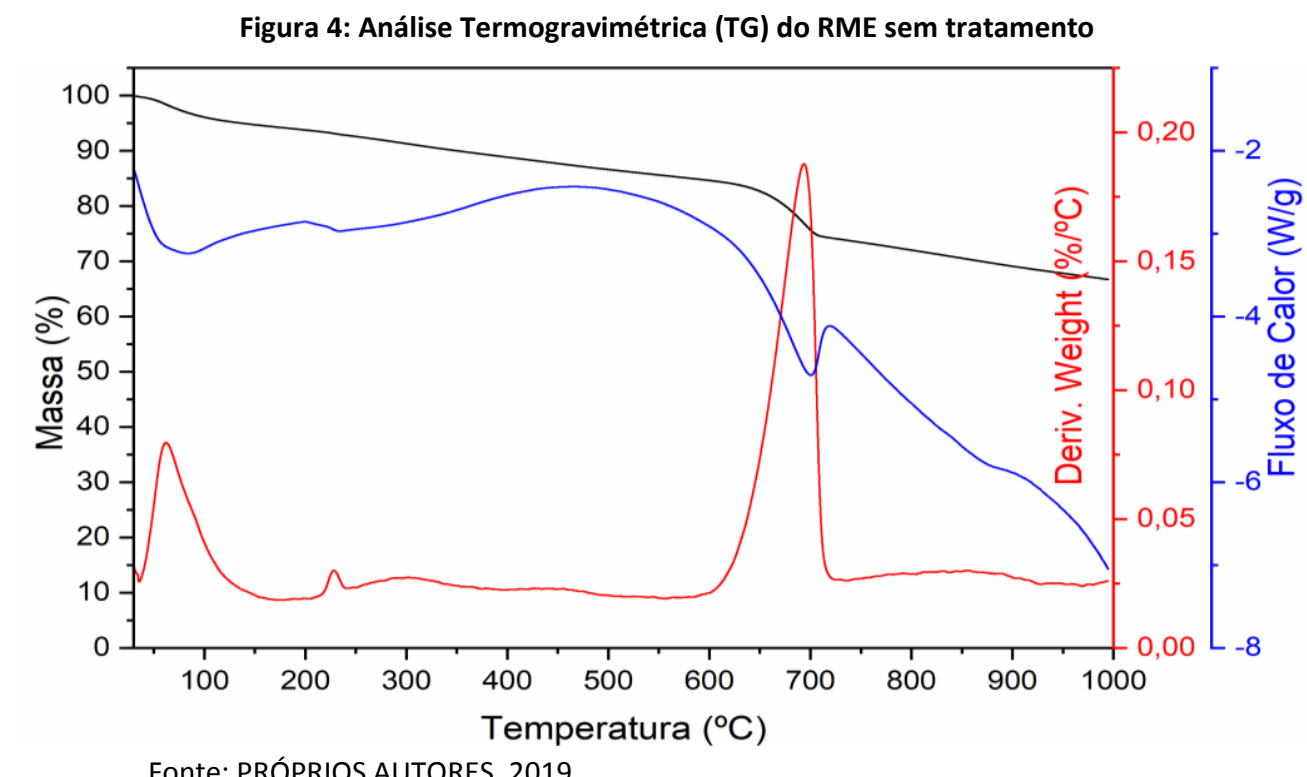

Fonte: PRÓPRIOS AUTORES, 2019.

As curvas na coloração preta e vermelha representam as curvas de perda de massa (TG) e sua derivada (DTG), respectivamente. Já a curva na cor azul representa a curva de fluxo de calor referente a medida de calorimetria exploratório diferencial (DSC).

Na curva preta (TG) tem-se que cada "step" é dado pelos estágios de perda de massa que podem ser devido a evaporação, decomposição e degradação, por exemplo. Devido à dificuldade de se verificar estes processos de degradação dos componentes existentes na amostra por meio do TG, tem-se que este procedimento é facilitado pela derivada desta curva que é dado pela DTG, onde se tem os picos acentuados representando esse processo de perda de massa.

A curva de degradação térmica da amostra RME apresentou basicamente 3 estágios de degradação: o primeiro situado entre $20^{\circ} \mathrm{C}-140^{\circ} \mathrm{C}$ foi atribuído a evaporação de água. $\mathrm{O}$ segundo estágio de degradação, composto de múltiplos processos, entre $140^{\circ} \mathrm{C}$ à $600^{\circ} \mathrm{C}$ foi atribuído a degradação principal de matéria orgânica residual do processo de queima industrial; e o terceiro processo de degradação, por sua vez, situado entre 600 e $720^{\circ} \mathrm{C}$ está relacionado à região de degradação do carbonato de cálcio ( $\mathrm{CaCO} 3)$ que é o composto predominante na amostragem.

Analisando a curva azul dado pela calorimetria exploratória (DSC), que indica o fluxo de calor na amostra, tem-se que este processo de transferência se dá de duas formas, sendo elas a absorção e a liberação de calor. A absorção é dada por uma reação endotérmica em que há o consumo de calor e, portanto, não sendo tão vantajoso para o projeto em si que envolve geração de energia. Já a liberação de calor, por sua vez, é um processo exotérmico. As reações que envolvem absorção (endotérmica) e liberação (exotérmica) possuem curvas voltadas para baixo e para cima, respectivamente, e podem ser facilmente visualizadas pela Figura 6 . Na 


\section{ANAP

faixa de temperatura de $20^{\circ} \mathrm{C}$ à $140 \circ \mathrm{C}$ tem-se que o processo de degradação da água (evaporação) é tipicamente endotérmico. Já na faixa de $1400^{\circ} \mathrm{C}$ à 600 으, tem-se que a queima da matéria orgânica é um processo exotérmico com consequente liberação de calor e, portanto, geração de energia para o sistema. Por fim, na faixa de $600^{\circ} \mathrm{C}$ à $720^{\circ} \mathrm{C}$ tem-se a degradação do carbonato de cálcio ( $\mathrm{CaCO}$ ) é um processo endotérmico com eventual consumo de energia.

Além da análise termogravimétrica (TG) para as cinzas brutas e sem tratamento, fez-se a análise das cinzas do resíduo da madeira de eucalipto pura, porém calcinada, de tal forma que pode ser verificada abaixo por meio da Figura 5.

Figura 5: Análise Termogravimétrica (TG) do RME calcinado

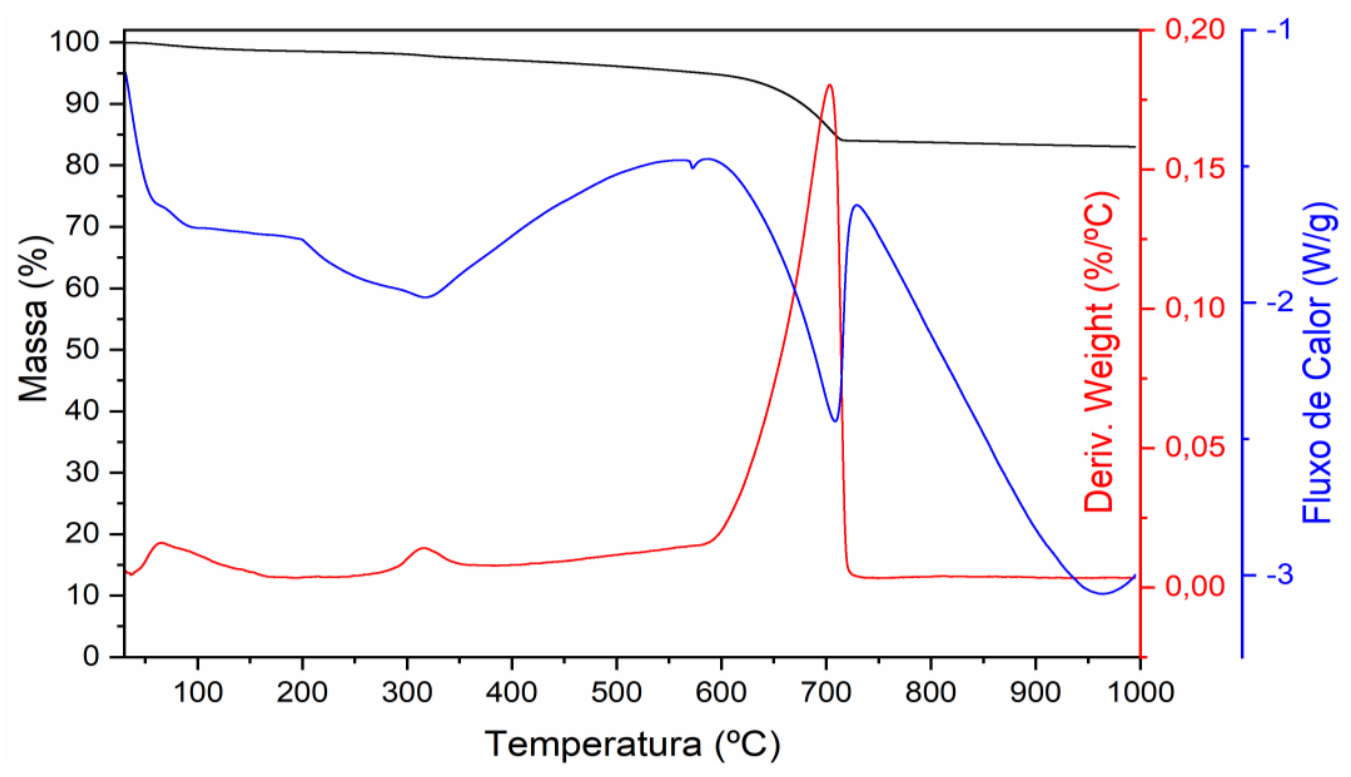

Fonte: PRÓPRIA AUTORIA, 2019.

Por meio da análise da derivada da curva de TG, tem-se que na faixa de $20^{\circ} \mathrm{C}$ à $1400^{\circ} \mathrm{C}$ há a degradação da água em menor escala se comparado a degradação deste composto na figura anterior, provavelmente advinda do processo de armazenagem. Pode-se verificar ainda a presença de um pico em torno de 320 ㄷ $\mathrm{C}$ o que pode estar relacionado aos óxidos formados, ou seja, óxido de cálcio $(\mathrm{CaO})$ e magnésio $(\mathrm{MgO})$. Além disso, tem-se que houve a degradação efetiva da matéria orgânica na faixa de temperatura entre $140 \circ \mathrm{C}$ e $600{ }^{\circ} \mathrm{C}$, pois o pico relacionado a esta composição não aparece na análise térmica do RME calcinado. Por fim, tem-se um pico acentuado na região de $600^{\circ} \mathrm{C}$ à $720^{\circ} \mathrm{C}$ relacionado ao carbonato de cálcio (CaCO3), indicando uma descarbonatação parcial do material, assim como evidenciado nas amostras de DRX. 


\section{REVISTA CIENTÍFICA 2020}

\subsection{PRODUÇÃO DOS BRIQUETES COM O RME}

Foram moldados briquetes de dimensões $5 \times 5 \times 5 \mathrm{~cm}$. Neste processo de moldagem foram misturados o resíduo (RME) juntamente com o aglutinante amido de milho em diferentes porcentagens e água. Utilizou-se, portanto, o ligante nas seguintes proporções: 5\%, 10\% e 15\% em relação à massa de resíduo utilizada no ensaio, bem como foram feitos corpos-de-prova sem a adição do aglutinante. Após vários testes em laboratório, chegou-se à conclusão que a proporção de água adequada para montar os briquetes foi 1:1 de água em relação à massa das cinzas. A Figura 6 a seguir exemplifica a mistura feita em laboratório.

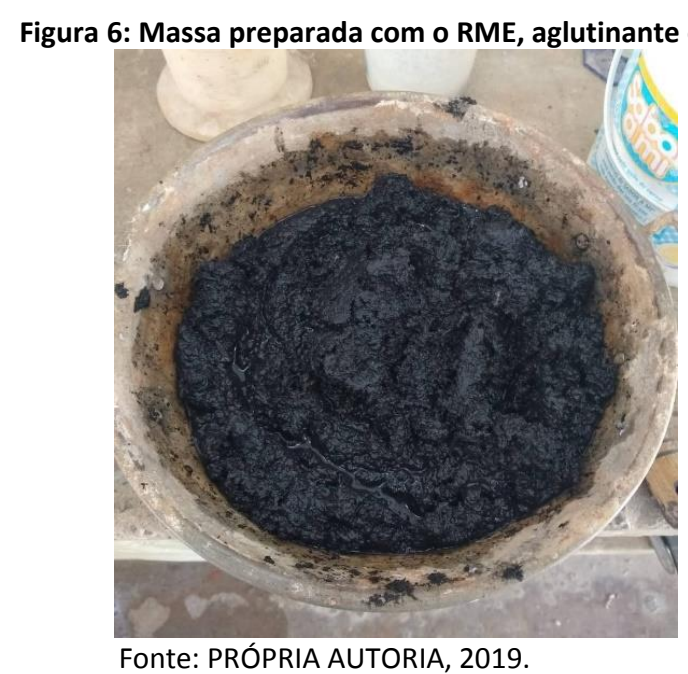

Em seguida, depois de determinar os traços, e com as misturas nas diferentes porcentagens de ligantes feitas, encaixou-se a fôrma na prensa manual de tijolos como pode ser verificado pela Figura 7 abaixo. Esta fôrma tem a capacidade de moldar oito corpos-de-prova de $5 \times 5 \times 5 \mathrm{~cm}$ cada cubo. Após esta etapa, colocou-se a mistura na fôrma e comprimiu-se a mesma por meio do auxílio da prensa manual formando, portanto, os briquetes que podem ser visualizados pela Figura 8 e que posteriormente foram desmoldados de acordo com a Figura 9. 


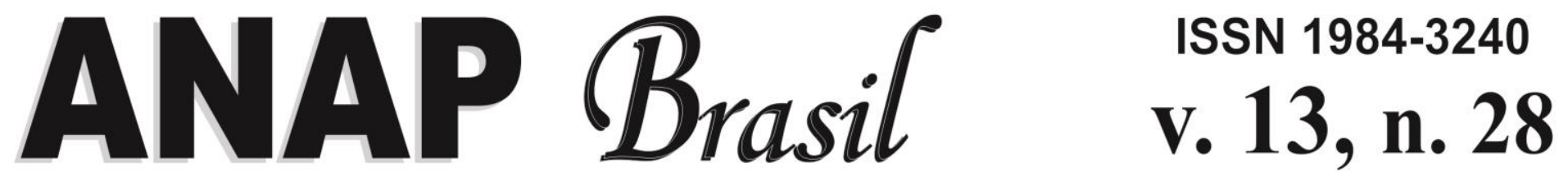

\section{REVISTA C I E N TÍF I CA $\quad 2020$}

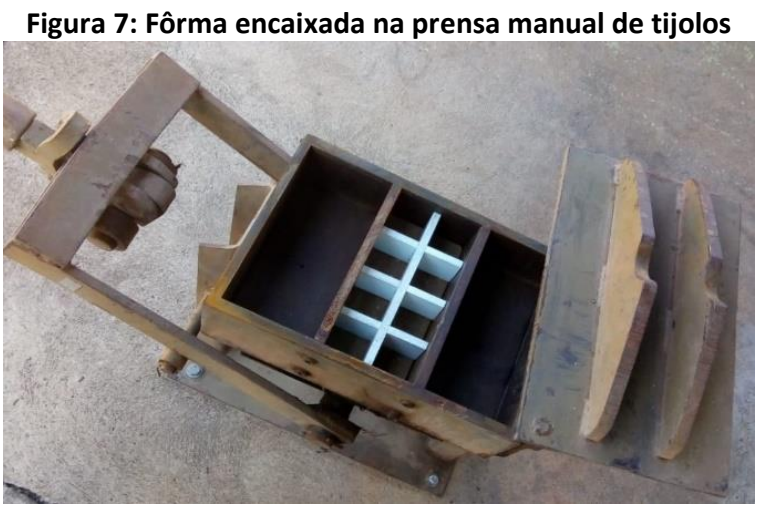

Fonte: PRÓPRIA AUTORIA, 2019.

Figura 8: Briquetes moldados

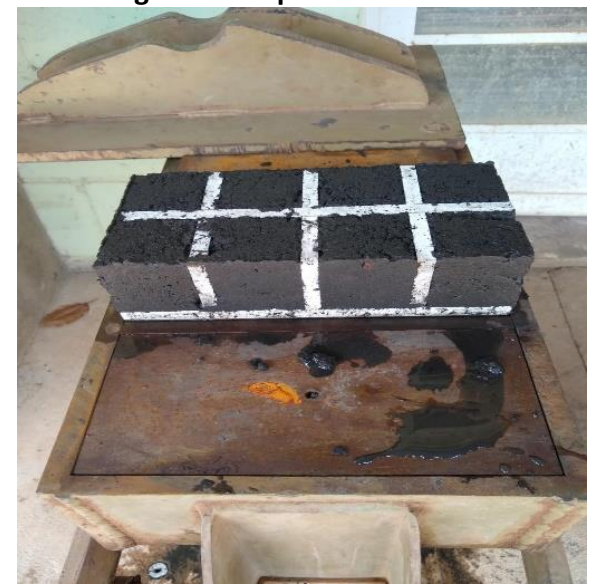

Fonte: PRÓPRIA AUTORIA, 2019.

Figura 9: Briquetes desmoldados e secos

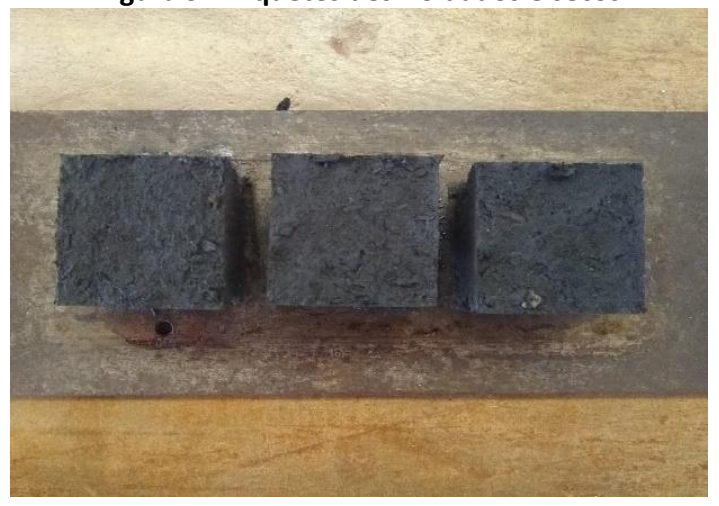

Fonte: PRÓPRIA AUTORIA, 2019.

A cerca desta experimentação, pode-se discutir que foi possível montar um biocombustível sólido por meio do processo de briquetagem com o RME, água e amido de milho para as diferentes porcentagens de aglutinante, assim como também sem o mesmo cujas quantidades foram definidas empiricamente. Notou-se, como já esperado, que os briquetes formados pela 


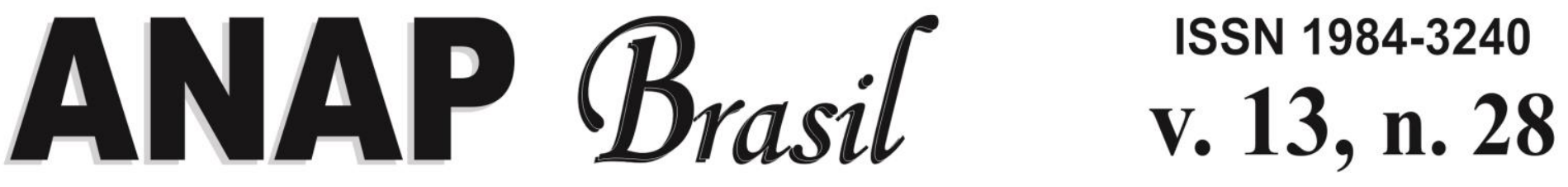

\section{REVISTA C I ENTÍF I CA $\quad 2020$}

cinza, água e $15 \%$ do ligante em relação a massa de fuligem se mostrou mais coeso, embora as outras composições não apresentaram grandes dificuldades para moldar. Desta forma, tornase economicamente viável montar corpos-de-prova sem o ligante visto que, barateia o custeio de implantação, bem como não houve alteração significativa no processo de confecção dos briquetes

Após o processo de briquetagem descrito acima, os corpos de prova foram calcinados como descrito na metodologia e o resultado é mostrado na Figura 10.

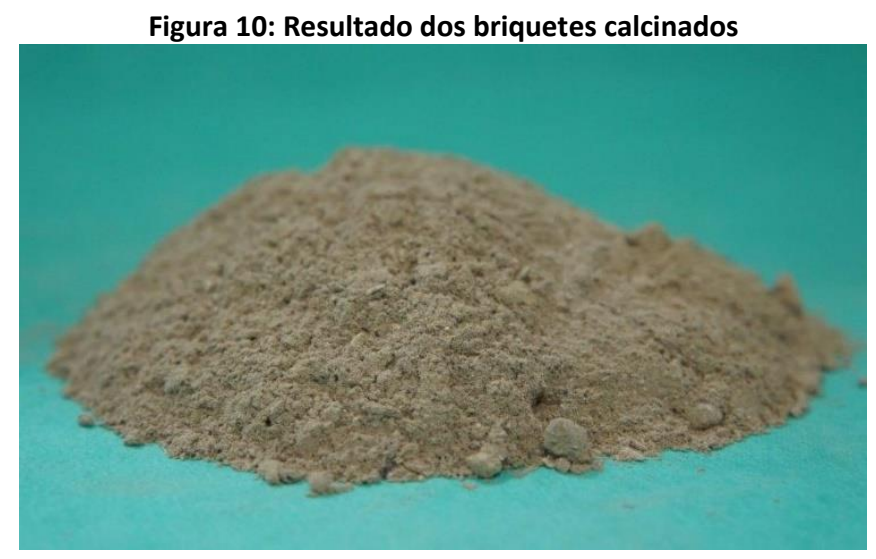

Fonte: PRÓPRIA AUTORIA, 2019.

A Figura 11 ilustra os padrões de DRX para os briquetes calcinados.

Figura 11: Difratograma de raio-x dos briquetes moldados

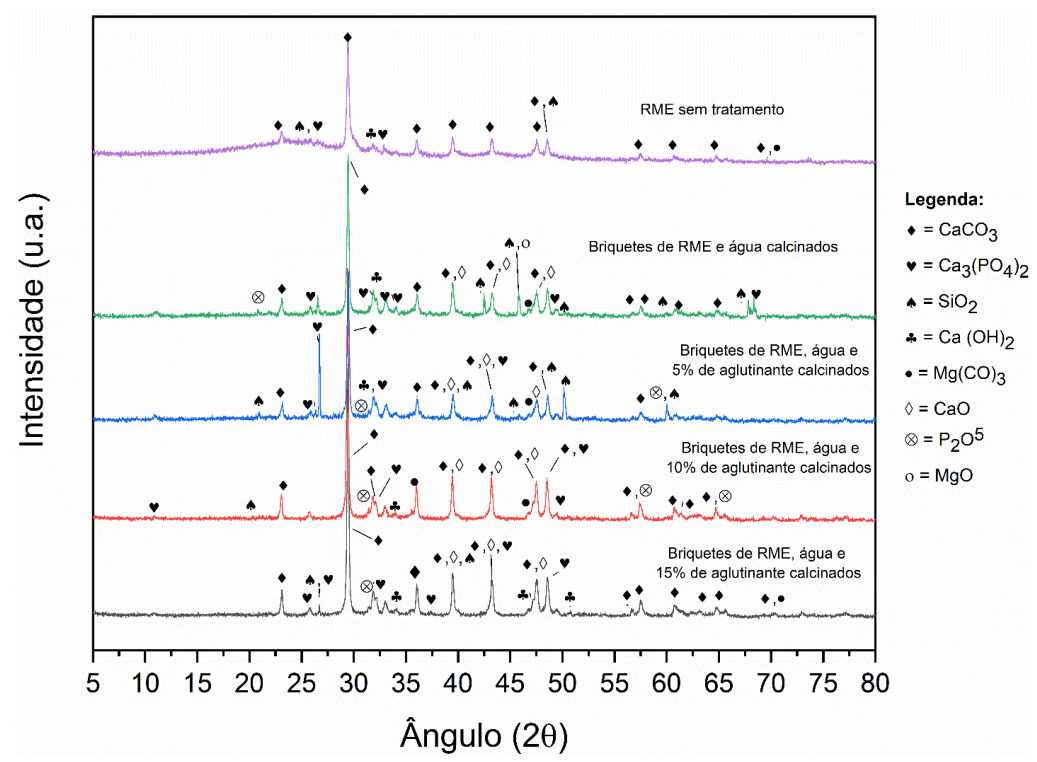

Fonte: PRÓPRIA AUTORIA, 2019. 


\section{REVISTA CIENTÍFICA}

Analisando comparativamente os padrões de DRX dos briquetes moldados em laboratório e calcinados com o RME puro e sem calcinar, tem-se que houve a degradação da matéria orgânica, uma vez que, a banda amorfa aparece apenas na curva em lilás que é da fuligem não tratada. Além disso, observou-se a presença de óxido de cálcio $(\mathrm{CaO})$ para ambas amostragens.

\section{CONCLUSÃO}

Pode-se dizer que as cinzas da madeira de eucalipto oriunda da Cooperativa Agroindustrial dos Produtores Rurais do Sudoeste Goiano (COMIGO), durante o processo de produção de óleo de soja, possuem alto teor de matéria orgânica, caracterizada, principalmente, pela presença do elemento carbono $(\mathrm{C})$ e sua composição predominante de carbonato de cálcio (CaCO3), comprovada pela difração de raio-x (DRX). Além disso, no que tange ao caráter visual, tem-se que estas cinzas possuem coloração preta e que são típicas de materiais com alto teor de carbono e que este processo de maior ou menor porcentagem presente nas amostras está diretamente relacionada à calibração dos fornos e caldeiras e, portanto, a eficiência da degradação térmica da madeira de eucalipto.

Pela análise das cinzas da lenha do eucalipto, bem como pela análise dos briquetes, ambos calcinados em forno Mufla à $600^{\circ} \mathrm{C}$ por $6 \mathrm{~h}$, verificou-se que houve a degradação total da matéria orgânica residual e que este processo é exotérmico com consequente liberação de calor e, portanto, geração de energia comprovados pela análise de DSC. Além disso, verificouse que houve a descarbonatação parcial, visto que nestas amostras, foram encontrados subprodutos oriundos da degradação do carbonato de cálcio ( $\mathrm{CaCO})$ em óxido de cálcio ( $\mathrm{CaO}$ ), assim como houve a degradação do carbonato de magnésio (MgCO3) em óxido de magnésio ( $\mathrm{MgO}$ ). No que tange ao caráter visual, tem-se que estas cinzas calcinadas possuem coloração cinza-claro e que são típicas de materiais com óxido de cálcio ( $\mathrm{CaO})$.

Por fim, pode-se concluir que foi possível montar um biocombustível sólido com propriedades e capacidade de gerar energia de maneira sustentável e que seja economicamente viável, dando um descarte adequado às toneladas de resíduos que são descartadas de maneira inadequada, podendo poluir o meio ambiente, bem como pode ser prejudicial à saúde humana. Além disso, verificou-se empiricamente que o custo de implantação pode ser barateado pela não utilização de ligante na confecção dos briquetes, visto que, não há uma alteração significativa das propriedades quando se utiliza o mesmo. Além disso, tem-se que a utilização deste resíduo para a geração de energia no processo fabril da indústria reduziria potencialmente a quantidade de árvores a serem cortadas sendo, portanto, mais um motivo favorável à implantação.

\section{AGRADECIMENTO}

Em primeiro lugar a Deus por ter me orientado e concebido várias oportunidades. Aos meus pais e familiares. Ao meu orientador Prof. Dr. Jorge Luis Akasaki e ao coorientador Alex Otávio Sanches pelos ensinamentos, orientações e por confiarem no meu trabalho. E, por fim, a FAPESP por financiar o meu projeto de pesquisa. 


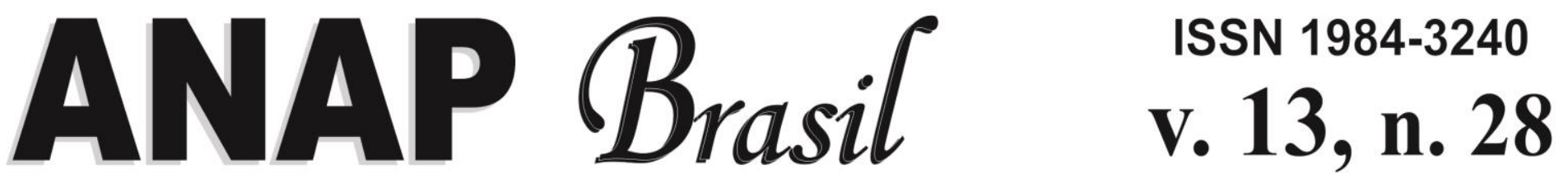

\section{REVISTA C I E N TÍFICA $\quad 2020$}

\section{REFERÊNCIAS}

ASSOCIAÇÃO BRASILEIRA DE PRODUTORES DE FLORESTAS PLANTADAS - ABRAF. Anuário estatístico da Abraf 2012 ano base 2011. Brasília, 2012. Disponível em: < http://www.ipef.br/estatisticas/relatorios/anuario-abraf12-br.pdf>. Acesso em: 20 de Outubro de 2019.

BORTOletTO, M., GUIMARAES, P.V.C, SILVA, R.G., AKASAKI, J. L. Avaliação do resíduo da Cinza da Madeira de Eucalipto como substituição parcial da areia em argamassas de cimento. Volume 10, no 18, 2017.

BRITO, J. O. O uso energético da madeira. Estudos Avançados. São Paulo, v. 21, n. 59, Abr. 2007. Disponível em < http://www.scielo.br/pdf/ea/v21n59/a14v2159.pdf >. Acesso em: 20 Outubro de 2019.

COELHO, S. T. Biofuels - Advantages and Trade Barriers. In: UNITED NATIONS CONFERENCE ON TRADE AND DEVELOPMENT, 2005, Genebra. Disponível em: <http://www.unctad.org/en/docs/ditcted 20051_en.pdf>. Acesso em: 21 de Outubro de 2019.

DEMIRBAS, A. Potential applications of renewable energy sources, biomass combustion problems in boiler power systems and combustion related environmental issues. Prog. Energy Combust. Sci. 2005, 31, 171-192.

DUAN, L.; LIU, D.; CHEN, X.; ZHAO, C. Fly ash recirculation by bottom feeding on aa circulating fluidized bed boiler co-burning coal sludge and coal. Appl. Energy 2012, 95, 295-299.

GOLDEMBERG, J.; VILLANUEVA, L. D. Energia, Meio Ambiente \& Desenvolvimento. São Paulo: Ed. USP, 2003. 226 p. GOMES-BAREA, A.; VILCHES, L.; CAMPOY, M.; FERNANDEZ-PEREIRA, C. Plant optimization and ash recycling in fluidised waste gasification. Chem. Eng. J. 2009, 146, 227-236.

GONZALEZ, A. D. Caracterização e análise comparativa de cinzas provenientes da queima de biomassa. $2014.70 \mathrm{f}$. Dissertação (Mestrado) - Curso de Engenharia Mecânica, Universidade Estadual de Campinas, Campinas, 2014. INTERNATIONAL ENERGY AGENCY - IEA. World Energy Investment Outlook 2003. France: IEA, 2003. 530 p.

JACOVINE, L. A. G.; MACHADO, C. C.; SOUZA, A. P.; LEITE, H. G. Avaliação da perda de madeira em cinco subsistemas de colheita florestal. Rev. Árvore, Viçosa, MG, v.25, n. 4, p. 463-470, 2001.

KHAN, A.; JONG, W.; JANSENS, P.; SPLIETHOFF, H. Biomass combustion in fluidized bed boilers: Potential problems and remidies. Fuel Process. Technol. 2009, 90, 21-50.

LÖVGREN, L. Roll pelletizing of ash - Cost efficient handling and improved product with accelerated carbonatization. In Procedings of Conference on Ash Utilization 2012: Ashes in a Sustainable Society, Stockholm, Sweden, 25-27 January 2012. 


\section{REVISTA CIENTÍFICA 2020}

SANTIAGO, F. L. S. Aproveitamento de resíduos florestais de Eucalyptus spp na indústria de fabricação de celulose para geração de energia térmica e elétrica. 2013. 109 f. Tese (Doutorado) - Curso de Agronomia, Universidade Estadual Paulista "Júlio de Mesquita Filho", Botucatu, 2013.

SOARES, C. P. B.; NETO, F. P.; SOUZA, A. L. Dendrometria e inventário florestal. 2. ed. Viçosa: Universidade Federal de Viçosa, Viçosa, MG. 2011. 272 p.

WALTER, A. Estado de arte das tecnologias de alto desempenho de produção de eletricidade a partir da biomassa. Agência Nacional de Energia Elétrica (ANELL), disco compactado digital. 82293252-246, São Paulo, 1998. 